\title{
THE UNIFIED STATE EXAM 2014: THE MAIN RESULTS
}

\author{
T.Klyachko
}

In 2014, unprecedented measures of control were taken in passing of the unified state exam (USE). That situation produced immediately both some expected and unexpected results.

For the first time since 2009 - when the USE became a routine mode - no scandals in holding of the USE took place. There were neither leaks of answers in the Internet, nor large-scale copying off, or strong public protests over violations in holding of the USE, or demands to abolish it in the near future.

In addition to the above, the mass media has ceased to discuss the issue of damage of the USE to the Russian education and the quality of test materials and procedures for calculation of test grades.

It can be stated that the absence of scandals at the USE reconciled to it at once teachers, parents, school leavers and even deputies who used often to win a reputation by criticizing the USE.

What is behind such a reconciliation with the USE and what is the price of it? It is easy to judge about the financial costs because the Ministry of Science of the Russian Federation released the data on the costs incurred: $\mathrm{Rb} 600 \mathrm{~m}$ and $\mathrm{Rb} 63 \mathrm{~m}$ were spent on equipment of rooms where the USE was held with surveillance cameras $(46,000$ cameras were installed) and supervision over delivery of examination materials to a number of problem regions, respectively.

However, it appears that measures of a nonmaterial nature produced a greater effect. Firstly, soon after the notorious campaign of 2013 a few managers of regional education authorities were dismissed. That was a clear signal to the education community that failures to endeavor to prevent violations at the USE would be punished rigorously. So, such a practice of securing better results at the USE as a transfer of students of city schools to rural schools six or even a few months before completion of the $11^{\text {th }}$ form was eliminated. Secondly, tests were different in different time zones, so it was pointless to place them in the Internet. Thirdly, D.V. Livanov, Minister of Education and Science said it was inadmissible to assess regional and municipal education systems, as well as schools on the basis of the results of the USE. Fourthly, a change in the format of the USE for humanity subjects, particularly, a return of an essay as a kind of examination (or a pass to the USE), as well as introduction of a third mandatory USE, that is, a foreign language exam have been widely discussed of late.
All the above measures have yielded results: the USE has ceased to be a powerful social irritant. Also, it became apparent that the USE was utilized for political purposes where the main target of the propaganda campaign was not the USE itself, but the Minister of Education and Science (both A.A. Fursenko and D.V. Livanov), while the USE was a means of discrediting the Minister of Education. In addition to the above, it became absolutely clear that if there is a determination to put things right, it can be done the right way and very fast taking into account the fact that a large sum of budget funds was spent on holding of the USE since it was introduced; the sum of $\mathrm{Rb} 663 \mathrm{~m}$ is not a limit.

Arranging things the right way at the USE identified at once a number of problems in the Russian school education. They had to reduce the minimum admissible grade in math and that in the Russian language from 24 points to 20 points and from 36 points to 24 points, respectively, so that a school leaver could receive the secondary school diploma. It is to be noted, that the number of school leavers who failed both the mandatory exams (math and the Russian language) amounted to 5,000 persons against 6,500 a year before. However, if the minimum grades on the above subjects were not reduced, it is likely that the number of school leavers who failed to receive their diplomas would be larger than in 2013. According to D.V. Livanov, Minister of Education and Science: "if the threshold grade was the same as in 2013 the number of school leavers who failed their USE in the Russian language would amount to 28,000 , that is, about $4.2 \%$. After the threshold amount was reduced, the number of those who failed the exam was almost the same as in 2013 , that is, 10,500 school leavers" $^{\prime 1}$. It appears that the situation with a exam in math would have been the same. However, the explanations on that issue by S.A. Kravtsov, Head of the Rosobrnadzor was rather surprising: "Such a decision [to reduce the threshold grade - T.K] was related to the fact that many school students fail to pass that minimum threshold on that subject and if they do not receive the secondary school diploma they will not be able to go to higher educa-

1 http://www.gazeta.ru/social/2014/07/02/6095421.shtml 
tion establishments"1. So, the most important thing for education authorities was not the assessment of the real state of things in general education and identification with utilization of the USE of problems in instruction of at least mandatory subjects - math and Russian - but preservation of public peace. Actually, in Russia where higher education is a social norm, the situation where even $4 \%-5 \%$ of school leavers fail to receive their diplomas would have produced a highly negative reaction on the part of parents and teachers. It means that "a reconciliation with the USE" was ensured by means of a regular dramatic reduction of requirements to school leavers as regards mandatory subjects. The main reduction of requirements took place in 2009 when a transfer to the USE in a routine mode was ensured among other things by a reduction of the share of bad marks, for example, in math from $23 \%$ to $3.0 \%$ (Table 1 ).

Table 1

THE SHARE OF SCHOOL LEAVERS WHO RECEIVED "2 GRADES" ON A FIVE-GRADE SCALE ON MANDATORY SUBJECTS OF THE USE IN THE 2006-2010 PERIOD,\% ${ }^{2}$

\begin{tabular}{|l|c|c|c|c|c|}
\hline \multirow{2}{*}{ Subject } & \multicolumn{5}{|c|}{ «2» (on a five-grade scale) } \\
\cline { 2 - 7 } & 2006 & 2007 & 2008 & 2009 & 2010 \\
\hline Russian & 7.91 & 8.81 & 11.21 & 2.76 & 2.1 \\
\hline Math & 19.99 & 21.14 & 23.48 & 3.04 & 3.5 \\
\hline
\end{tabular}

Source: The Rosobrnadzor.

It is to be noted that from 2010 till 2013 the threshold (minimum admissible) values of grades on all the subjects were set by the Rosobornadzor in September preceding the year of the USE and were not changed in the process of holding of relevant exams. So, in 2014 a precedent was created and the results of the USE can now be adjusted to the specific conditions prevailing at the time of the USE.

At the same time, toughening of control resulted in a situation where the average grade on the USE was reduced considerably on all the subjects (Table 2 ).

In our view, a rather small reduction of the average grade on the Russian language looks strange as the Rosobnadzor had to reduce the minimum admissible grade on the Russian language from 36 to 24 points in order to prevent large-scale failures on the USE in that mandatory subject.

\footnotetext{
1 http://itar-tass.com/obschestvo/1266577

2 From 2011, the Rosobrnadzor stopped providing the information on conversion of the USE grades into a traditional five-grade scale.
}

Also, toughening of control at the USE resulted in a reduction of the number of school leavers with a high grade (that is those who received from 80 to 100 points) from 180,000 persons to 115,000 persons (a $36 \%$ decrease), while the number of those who received 100 points fell from 9,000 persons to 3,500 persons (a $61.5 \%$ decrease). As result, a competition between leading Russian higher education establishments for those school leavers who passed the Unified Exam with the best results is to intensify. It can be expected that in 2014 the results of the admission board will have an effect on the rating of higher education establishments on the basis of the USE grades which rating has been presented by the NRU HSE together with the RIA Novosti during the past few years.

Table 2

\section{AVERAGE GRADES ON THE SUBJECTS OF THE USE} IN 2014 AND 2013

\begin{tabular}{|l|c|c|}
\hline \multicolumn{1}{|c|}{ Subject } & $\begin{array}{c}\text { Average grade } \\
\text { in } 2014\end{array}$ & $\begin{array}{c}\text { Average grade } \\
\text { in } 2013\end{array}$ \\
\hline Math & 40 & 50 \\
\hline Physics & 46 & 55 \\
\hline Chemistry & 56 & 69 \\
\hline Biology & 54 & 59 \\
\hline Geography & 53 & 58 \\
\hline Computer Science & 57 & 63 \\
\hline English & 61 & 73 \\
\hline History & 46 & 56 \\
\hline Social Science & 53 & 60 \\
\hline Literature & 54 & 60 \\
\hline Russian & 63 & 64 \\
\hline
\end{tabular}

Source: The Rosobrnadzor.

An unbiased vision of the situation related to the USE should permit authorities in charge of education of constituent entities of the Russian Federation to develop programs of support (reorganization, to be more precise) of schools which showed poor USE results. It is to be stated that D.V. Livanov, Minister of Education spoke about the need to carry out that work (though he called for not to assess schools on the basis of the USE results).

Generally, the 2014 USE campaign showed that the quality of school education in Russia remains low (it is really getting worse as it has become clear that in the past few years the USE results were shifted largely towards higher values). At present, one can see the real state of things in education. Let us hope that remedies which can at least ease that difficult situation will be found. 